Este texto foi produzido por um grupo que estuda, reflete e questiona o trabalho clínico em instituiçōes e propõe-se a discutir as questooes relativas ao funcionamento das Entrevistas Iniciais (EI) da Clínica de Atendimento Psicológico (CAP) da UFRGS, seu histórico, conceito e modo de funcionamento na atualidade, visto ser esta a forma de recebimento e primeira escuta de pacientes nessa instituição. A partir disso, visa pensar as intercorrencias

institucionais que atravessam a escuta clínica desde - referencial psicanalítico. Entrevistas iniciais; clínica-escola; demanda; escuta clínica

\section{SPECIFICNESS OF THE} WORKING OF INITIAL INTERVIEWS

$A$ research staff of therapists from Clínica de Atendimento Psicológico (CAP), UFRGS, Brazil, produced this work. It attempts to develop a discussion between the psychoanalytical clinical service and an institution. It discusses the working of the Initial Interviews (El) at UFRGS's Clinic, its theoretical and practical context, and its specificness and dissimilarities related to other kinds of preliminary interviews or sorting. Finally the staff attempts to raise questions about the application of the psychoanalytical theory in an institutional context, from this mechanism of reception and first listening of patients (El) at the referred institution. Initial interviews; schoolclinic; demand; clinical listening

\section{ESPECIFICIDADES \\ NO TRABALHO DE ENTREVISTAS INICIAIS}

\author{
Déborah da Silva Minuzzi \\ Roberto Henrique Amorim de Medeiros \\ Suzana Chotgues Boklis \\ Suzana Reis Coelho \\ Mirela de Cintra
}

A Clínica de Atendimento Psicológico (CAP) da Universidade Federal do Rio Grande do Sul foi inaugurada há 22 anos. Caracterizada como um órgão público federal, é vinculada ao curso de Psicologia daquela universidade e propõe-se ao atendimento psicológico de pessoas da comunidade que

Psicóloga com especialização em atendimento clínico, ênfase em psicanálise, pela Clínica de Atendimento Psicológico (CAP) da

UFRGS; membro da equipe técnica da CAP da UFRGS.

Psicólogo com especialização em atendimento clínico, ênfase em psicanálise, pela CAP da UFRGS; extensionista da CAP da UFRGS; mestrando em Psicologia Clínica na PUC-RS.

口صsicóloga com especialização em atendimento clínico, ênfase em psicanálise, pela CAP da UFRGS; membro do Centro Clínico

Thiago Würth (Canoas, RS).

[D. Psicóloga com especialização em atendimento clínico, ênfase em psicanálise, pela CAP da UFRGS (em cursol; extensionista da CAP da UFRGS.

口耳u Psicóloga com especialização em atendimento clínico, ênfase em psicanálise, pela CAP da UFRGS. 
não têm acesso aos consultórios privados ou não encontram lugar na rede pública de serviços de saúde.

É preciso situá-la, também, como importante órgão de ensino, pesquisa e prática clínica: propicia estágios em psicologia clínica e psicologia escolar (na área de psicopedagogia) e estágio em fonoaudiologia; oferece curso de especialização em atendimento clínico com ênfase em psicanálise, em terapia familiar sistêmica e, mais recentemente, em psicopedagogia clínica. Conta com a participação de diversos profissionais, que atendem, supervisionam e administram o trabalho ali desenvolvido, sendo o referencial psicanalítico o principal eixo teórico norteador e organizador da CAP.

Uma das características diferenciais da CAP é a forma pela qual os pacientes iniciam seu atendimento. $\mathrm{O}$ termo Entrevistas Iniciais (EIs) designa esse processo de recebimento ou primeira escuta das pessoas que procuram a Clínica. Trata-se de uma "construção" teórica e prática dessa instituição (Brizio \& Petry, 1994) e diferenciase das Entrevistas Preliminares e Entrevistas de Triagem.

Entrevista Preliminar é um conceito psicanalítico e acontece num primeiro momento de uma possível análise. Assemelha-se às EIs, pois não há um tempo determinado de duração, e diferenciase destas, porque não ocorre troca de terapeuta, havendo, assim, continuidade entre as Entrevistas Preliminares e a análise propriamente dita. Nas Entrevistas de Triagem, o que ocorre é um primeiro atendimento, muitas vezes em grupos, em que o processo diagnóstico é priorizado e de forma bem mais rápida que nas EIs.

Quando uma pessoa chega à CAP, é atendida por um terapeuta que faz parte da equipe das EIs durante um período de tempo não estabelecido a priori, no qual será proporcionada uma primeira escuta da sua queixa, além de esclarecimentos do funcionamento institucional. Nesse período podem ocorrer interconsultas e encaminhamentos necessários ao caso (atendimento ou avaliação em psicopedagogia, terapia familiar, fonoaudiologia e psiquiatria), podendo resultar em tratamento psicológico associado ou não a outras especialidades. "É um tempo necessário para transformar essa queixa, que vem dirigida à instituição como um todo, em um pedido de tratamento com um terapeuta" (Minuzzi, 1999).

Como foi descrito, as EIs envolvem um período de tempo mais longo que o processo de triagem, e o trabalho é desenvolvido por uma equipe de profissionais graduados, que fazem parte dos cursos de especialização ou extensão, e que, portanto, já possuem um maior percurso de escuta clínica. $\mathrm{Na}$ medida em que a fala do paciente é privilegiada como possibilidade de singularizar o pedido de ajuda, faz-se necessária uma maior sutileza na escuta, além de precisão na condução dos casos, já que muitas vezes os encami- 
nhamentos que chegam de outras instituições ou de outros profissionais não constituem um pedido de tratamento. Isso também acontece com aqueles pacientes que chegam com uma queixa, e não com uma demanda de tratamento. Nas EIs procura-se trabalhar essa queixa difusa ou o encaminhamento, viabilizando uma vinculação do paciente ao tratamento, fazendo aparecer uma outra dimensão de sua queixa e uma nova relação com seu sintoma.

Ao final do processo de EI, o paciente pode ser encaminhado para consultório privado, para outras instituições, ter seu atendimento encerrado e, o que é mais comum, continuar o tratamento com outro terapeuta da instituição, tendo que, freqüentemente, aguardar para tanto.

Grande parte dos atendimentos das Els e da Clínica é de crianças, que, na maioria dos casos, são encaminhadas pela escola (problemas de aprendizagem ou de comportamento) ou por algum profissional da área de saúde. Em geral, é no atendimento de crianças que são feitas interconsultas (com professores, orientadores, neurologistas, etc.) e avaliações em outras áreas (psicopedagogia, fonoaudiologia, terapia familiar) para que se possa fazer um diagnóstico diferencial.

Normalmente, os pais chegam até a Clínica sem uma demanda definida e, até mesmo, sem reconhecer na queixa da escola ou na avaliação médica do filho(a) uma questão para o atendimento psicológico. Nas EIs procura-se, então, esclarecer com os pais - em geral quem procura é a mãe - o motivo da procura pelo atendimento e, se constatada na criança alguma questão que "mereça" intervenção ou continuidade de algum atendimento (psicológico, psicopedagógico, fonoaudiológico ou em terapia familiar), trabalhar com os pais a transformação dessa queixa do outro em uma questão sua, podendo assim, viabilizar o tratamento.

Constatamos, a partir da prática cotidiana, que o processo de EI é um dispositivo muito importante na CAP, porque, além de uma primeira escuta do paciente, permite organizar a questão do sujeito em meio ao emaranhado de queixas que podem vir tanto dele como dos familiares, de outros profissionais ou instituições, viabilizando um futuro tratamento.

Em um processo tão específico como esse, algumas dificuldades podem surgir. Durante longo tempo as Entrevistas Iniciais possibilitaram uma escuta para todos que procuravam atendimento; atualmente, verifica-se que isso já não é possivel, pois o aumento da procura fez crescer muito o tempo de espera para um atendimento posterior às EIs. Com isso, passou-se a ter que suspender o recebimento de pacientes algumas vezes ao ano e, no período restante, tem se limitado o número de pacientes novos atendidos a cada semana.

$\mathrm{O}$ crescente número de pacientes que permanecem em atendimento configura-se, também, como outro aspecto que tem aumenta- 
do essa espera. Por uma série de fatores, o tempo de permanência na instituição tem se dilatado bastante, o que não é comum em clínicas-escola: A possibilidade de recepção dos pacientes existe, mas enfrentamos dificuldades para dar continuidade aos tratamentos desses pacientes após as EIs.

Em decorrência desses fatores, um dos pontos a serem considerados, e que interfere na escuta clínica, é a possível resistência do terapeuta de EI, após um trabalho de transformação de queixa em demanda, a colocar o paciente em espera, o que pode resultar num prolongamento do atendimento em EI, mesmo que o paciente já tenha formulado um pedido de tratamento.

A espera e a continuidade do tratamento têm sido umas das maiores preocupações da equipe das Entrevistas Iniciais e motivo de bastante angústia, a qual é trabalhada, junto com esses temas recorrentes, semanalmente nas reuniões e supervisões das EIs. Tal preocupação intensifica-se quando o atendimento se dá com crianças, visto que esta é uma fase bastante dinâmica no processo de estruturação subjetiva e cognitiva. Quanto maior a demora na intervenção, mais podem-se agravar os sintomas e dificuldades no processo de estruturação. Apesar dessa espera, procura-se escutar a singularidade de cada caso, pondo-se a questão clínica como prioridade nos encaminhamentos ao buscar-se alternativas para a continuidade dos tratamentos.

Podemos dizer que as Entrevistas Iniciais são um processo particular dessa instituição que lhe possibi- lita organizar-se a partir do referencial teórico da psicanálise. Alia a necessidade de dar conta de uma grande demanda externa, que busca tratamento clínico especializado, com o interesse e as possibilidades internas de prestar um bom atendimento a essa população.

Se tivermos em mente que a psicanálise só pode ser desenvolvida na sua forma clássica, não vislumbramos, então, trabalho possível na instituição. Porém, se pensarmos no referencial teórico e na escuta analítica, escuta possivel desde outro lugar que não um lugar político, econômico e social, uma escuta do sofrimento e da singularidade de quem vem falar, aí sim poderíamos acreditar no trabalho desenvolvido. $\mathrm{O}$ direito de ser escutado é dado a quem realmente quer ser escutado, e isso implica um grande investimento por parte do paciente e também do terapeuta.

\section{REFERÊNCIAS BIBLIOGRÁFICAS}

Brizio, M. \& Petry, P. (1994). As Entrevistas Iniciais na Clínica de Atendimento Psicológico da UFRGS: limites e possibilidades. Questão - Revista da Clínica de Atendimento Psicológico da UFRGS, $\mathrm{n}^{2}$ 1, dezembro.

Minuzzi, D. (1999). Transferência e instituição. Monografia de Conclusão do Curso de Especialização em Atendimento Clínico com ênfase em psicanálise da Clínica de Atendimento Psicológico da Universidade Federal do Rio Grande do Sul, Porto Alegre, RS.

Recebido em 06/2000. 